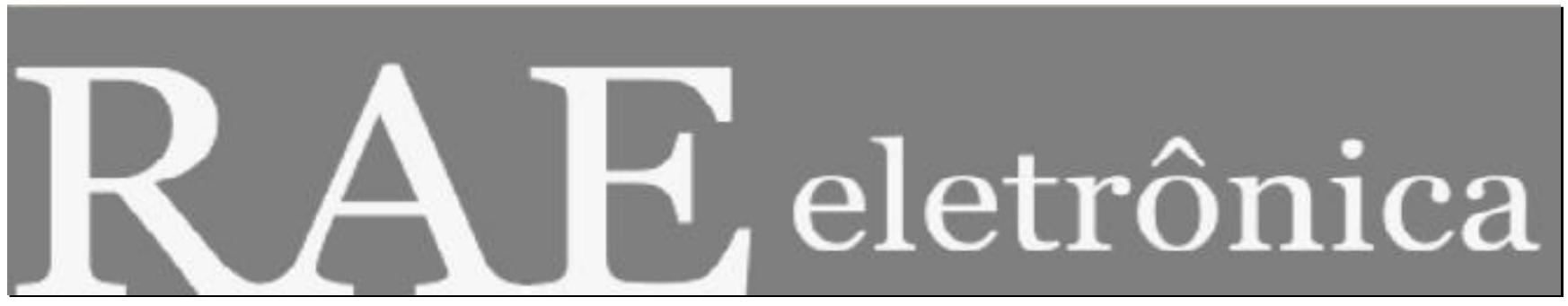

\title{
ORGANIZAÇÃO CIENTÍFICA DO TRABALHO REINVENTA UM MERCADO TRADICIONAL: O CASO DO FITNESS
}

Por:

Ivan Antônio Pinheiro, UFRGS.

Rodrigo Reszka Pinheiro, CEPUTEC.

RAE-eletrônica, v. 5, n. 2, Art. 15, jul./dez. 2006

http://www.rae.com.br/eletronica/index.cfm?FuseAction=Artigo\&ID=3359\&Secao=ARTIGOS\&Volu $\mathrm{me}=5 \&$ Numero $=2 \& \mathrm{Ano}=2006$

CCopyright, 2006, RAE-eletrônica. Todos os direitos, inclusive de tradução, são reservados. É permitido citar parte de artigos sem autorização prévia desde que seja identificada a fonte. A reprodução total de artigos é proibida. Os artigos só devem ser usados para uso pessoal e nãocomercial. Em caso de dúvidas, consulte a redação: raeredacao@ fgvsp.br.

A RAE-eletrônica é a revista on-line da FGV-EAESP, totalmente aberta e criada com o objetivo de agilizar a veiculação de trabalhos inéditos. Lançada em janeiro de 2002, com perfil acadêmico, é dedicada a professores, pesquisadores e estudantes. Para mais informações consulte o site www.rae.com.br/eletronica.

RAE-eletrônica

ISSN 1676-5648

(C2006 Fundação Getulio Vargas - Escola de Administração

de Empresas de São Paulo. 


\section{ORGANIZAÇÃO CIENTÍFICA DO TRABALHO REINVENTA UM MERCADO TRADICIONAL: O CASO DO FITNESS}

Ivan Antônio Pinheiro - Rodrigo Reszka Pinheiro

\section{RESUMO}

No setor de fitness, que cresce em expressão econômica, percebe-se um movimento que poderia sugerir um retrocesso: a adoção dos princípios e das técnicas da organização científica do trabalho (OCT) combinadas ao sistema de franquia, ambos práticas de gestão já consolidadas. Chama ainda a atenção o fato de o fenômeno ocorrer em um segmento supostamente refratário a essa adoção, sobretudo porque é valorizado como uma atividade artística em que predominam as competências pessoais, algumas tidas como habilidades inatas, efetivos talentos pessoais, a exemplo da criatividade. O objetivo principal deste trabalho é responder à seguinte questão: seriam a OCT, a criatividade e a inovação construtos incompatíveis entre si? Para realizar o seu intento, os autores combinam as informações coletadas em websites e entrevistas, bem como as suas próprias observações. Ao final, sugere-se que as repercussões no ambiente analisado, apesar de já se revelarem significativas, estão ainda em estágio inicial.

\section{PALAVRAS-CHAVE}

Organização científica do trabalho, franquia, globalização, fitness, mercado.

\section{ABSTRACT}

In the fast growing fitness industry the use of scientific organization of work might suggest a backward trend. These managerial practices are also associated with franchising as a business model. It is paradoxical because the industry is averse to the practices and to the business model as well because the fitness is valued as an artistic activity where personal skills, sometimes considered inborn, such as individual gifts and creativity should predominate. The main goal of this article is to answer the following question: are scientific organization of work, creativity and innovation compatible at all? The attempt to answer was made possible by visiting many websites, interviewing people and observingthe fitness businesses. It was found that at the organizational level the scientific organization of work is a limitation to creativity and innovation, but not eliminating them entirely. Thus the paradox remains and might bring further developments.

\section{KEYWORDS}

Scientific management, franchising, globalization, fitness, market. 


\section{ORGANIZAÇÃO CIENTÍFICA DO TRABALHO REINVENTA UM MERCADO TRADICIONAL: O CASO DO FITNESS}

Ivan Antônio Pinheiro - Rodrigo Reszka Pinheiro

\section{INTRODUÇÃO}

Em meio a um cenário em que ser inovador, atual e produtivo são conceitos freqüentemente associados à adoção das mais modernas tecnologias de informação, da automação e da organização do processo de trabalho segundo princípios da lean production, encontra-se um setor, que cresce continuamente em expressão econômica, mas que à primeira vista parece conter um elemento que sugere um retrocesso. Esse consistiria na adoção dos princípios e técnicas que integram a clássica organização científica do trabalho (OCT). Chama ainda a atenção o fato de o fenômeno observado estar ocorrendo em um segmento que se imaginava infenso a essas práticas. Primeiro porque é integrante do setor de serviços, que, devido às suas especificidades, nem sempre favorece a adoção dessas técnicas; segundo porque tem sido reconhecido e valorizado também como uma atividade artística caracterizada por atributos e competências pessoais, algumas tidas como inatas e talentos pessoais, como a criatividade. Por fim, observa-se que o seu célere avanço vem também modificando o modelo de negócio das academias de ginástica nos grandes centros urbanos, objeto deste artigo.

Feitas essas considerações, este trabalho se desdobra em quatro seções temáticas: 1) a organização científica do trabalho; 2) inovação e criatividade; 3) o caso do fitness; e 4) o fitness, a OCT, a criatividade e a inovação. Os temas na sequiência apresentada convergem para o objetivo principal deste trabalho, que é responder à seguinte indagação: a OCT, a criatividade e a inovação são construtos incompatíveis entre si? Ademais, pretende-se ainda demonstrar que práticas antigas, a exemplo da OCT e da franquia, quando combinadas, podem reconfigurar e inovar o modelo de negócios das academias de ginástica. Para realizar esse intento, os autores combinam dados primários e secundários. Tendo por base o marco de referência estabelecido a partir da revisão de literatura, as informações foram reunidas a partir de sites, depoimentos de profissio nais atuantes na área de educação física e de fitness. Entrevistou-se ainda o Coordenador de Atividades Físicas da Associação Cristã de Moços de Porto Alegre - RS (ACM-RS). Cabe ressaltar a condição de um dos autores, professor de educação física e praticante de fitness. Isso certamente ajudou muito na coleta de dados primários pela observação, pelo diálogo e pelo esforço de captar as percepções e sentimentos dos praticantes, com os quais convive diariamente há mais de cinco anos. Ademais, a convergência do conhecimento acadêmico e profissional de ambos tornou possível associar temas aparentemente tão diversos quanto a OCT, a criatividade-inovação e o fitness. Trata-se, portanto, de um estudo que pode ser caracterizado como um ensaio exploratório que aborda a questão investigada sob o enfoque eminentemente 
ORGANIZAÇÃO CIENTÍFICA DO TRABALHO REINVENTA UM MERCADO TRADICIONAL: O CASO DO FITNESS

Ivan Antônio Pinheiro - Rodrigo Reszka Pinheiro

qualitativo e adere ao que Brandão (2001) e Thiollent (apud Villa-Alvarez, 1988) identificam como pesquisa participante.

\section{ORGANIZAÇÃO CIENTÍFICA DO TRABALHO}

Pavel Gerencer, prefaciando o livro Princípios de Administração Científica, de Frederick Winslow Taylor (1987, p. 13), tributa ao autor a condição de "pai da organização científica do trabalho" (OCT), daí a importância de ser o primeiro a ser citado no trabalho que ora se inicia. A nosso ver, a origem da OCT pode ser identificada na obra Discurso do Método, publicado por R. Descartes em 1637. Nessa obra o autor descreve o seu caminho solitário e a absoluta escuridão na procura do verdadeiro método para chegar ao conhecimento de todas as coisas de que o espírito fosse capaz. O trecho a seguir é um clássico reproduzido em várias obras e bem introduz o tema que se pretende desenvolver:

O primeiro era o de nunca aceitar algo como verdadeiro que eu não conhecesse claramente como tal; ou seja, de evitar cuidadosamente a pressa e a prevenção, e de nada fazer constar de meus juízos que não se apresentasse tão clara e distintivamente a meu espírito que eu não tivesse motivo algum para duvidar dele. O segundo, o de repartir cada uma das dificuldades que eu analisasse em tantas parcelas quantas fossem possíveis e necessárias a fim de melhor solucioná-las. O terceiro, o de conduzir por ordem meus pensamentos, iniciando pelos objetos mais simples e mais fáceis de conhecer, para elevar-me, pouco a pouco, como galgando degraus, até o conhecimento dos mais compostos, e presumindo até mesmo uma ordem entre os que não se precedem naturalmente uns aos outros. E o último, o de efetuar em toda parte relações metódicas tão completas e revisões tão gerais nas quais eu tivesse a certeza de nada omitir (DESCARTES, 2000, p. 49-50).

A influência de Descartes (1596-1650) na obra de Adam Smith (1723-1790) é notável. Por exemplo, para descrever e analisar o impacto da divisão do processo de trabalho sobre a produtividade (à época o conceito de competitividade não era tão relevante como hoje), o autor recorre ao célebre exemplo da fabricação de alfinetes, processo que pode ser decomposto em 18 operações: corte, ponta, branqueamento e embalagem, entre outros. O autor relata que um trabalhador, sozinho, no máximo conseguiria produzir 20 alfinetes/dia. Se as operações fossem divididas e atribuídas a trabalhadores diferentes, ainda que um ou outro desempenhasse mais de uma atividade, a produção poderia chegar a 


\section{ORGANIZAÇÃO CIENTÍFICA DO TRABALHO REINVENTA UM MERCADO TRADICIONAL: O CASO DO FITNESS}

Ivan Antônio Pinheiro - Rodrigo Reszka Pinheiro

4.800 alfinetes/dia/homem, a exemplo do que observou em uma fábrica que empregava dez trabalhadores especializados. Na seqüência, o autor explica o motivo do que denomina de “considerável aumento de produção":

[...] primeiro, ao aumento da destreza de cada trabalhador; segundo, à economia de tempo, que antes era perdido ao passar de uma operação para outra; terceiro, à invenção de um grande número de máquinas que facilitam o trabalho e reduzem o tempo indispensável para realizá-lo, permitindo a um só homem fazer o trabalho de muitos (SMITH, 1979, p. 9).

Ainda atuais e relevantes, as observações de Adam Smith não lograram maior reconhecimento e difusão devido às condições de contexto, pois, à sua época, a Revolução Industrial se desenvolvia lentamente.

A síntese das recomendações de Descartes quanto a como proceder para chegar ao conhecimento, aliada às observações práticas e metódicas de Adam Smith, só veio a acontecer com F. W. Taylor (1856-1915). Sua obra mais famosa, publicada em 1911, teve grande acolhida e difusão porque, ao final do século XIX, os alicerces da Revolução Industrial já estavam assentados, bem como as suas consequiências, a saber: o aumento expressivo nas populações urbanas e o surgimento de variados setores e atividades industriais voltados para a satisfação de uma demanda crescente e diversificada. A forma de organizar e produzir, até então artesanal e pulverizada, cede espaço à organização industrial concentrada nas fábricas, o saber empírico ao saber científico, sendo que esse seria o único capaz de responder aos mvos volumes e à produtividade exigida para a satisfação das necessidades dos mercados em franca expansão. A preocupação com a produtividade, também referida como eficiência, atuará como leitmotiv na busca continuada de novas formas de organização e de gestão dos processos produtivos.

Nesse cenário, como resultado das várias experiências que realizou, Taylor (1987, p. 107) prescreve a sua proposta a partir do que denominou de os "quatro princípios fundamentais da Administração Científica":

- substituição do critério individual do operário por uma ciência;

- seleção e aperfeiçoamento científico do trabalhador, que é estudado, instruído, treinado e, pode-se dizer, experimentado, não mais escolhendo os processos e eventualmente aperfeiçoando-se por acaso; 
- cooperação íntima da administração com os trabalhadores, de modo que façam juntos o trabalho, de acordo com leis científicas desenvolvidas, em lugar de deixar a solução de cada problema, individualmente, a critério do operário;

- com a aplicação desses novos princípios, em lugar do antigo esforço individual, e com a divisão equânime, entre a direção e os trabalhadores, das partes de cada tarefa diária, a administração encarrega-se das atribuições para as quais está mais bem aparelhada e os operários encarregam-se das restantes.

O Taylorismo veio complementar a divisão dos processos de trabalho sugerida por Adam Smith e alçou a produtividade a níveis surpreendentes. Isso porque possibilitou a redução dos custos e o aumento dos volumes de produção pela padronização e pela otimização dos tempos e movimentos. Registraram-se ainda ganhos significativos no que tange à qualidade dos processos e produtos. Tendo apresentado bons resultados, o Taylorismo não encontrou obstáculos à sua rápida difusão (Neffa, 1990), por se apresentar como uma resposta ideal às necessidades do ambiente econômico de então. Inicialmente foi adotado pelas indústrias manufatureiras e se estendeu ao setor agrícola, ao comércio e, por fim, aos serviços. Morgan (1996), em análise mais contemporânea, identifica a presença do Taylorismo nas redes de fast food, bem como nas rotinas executadas nos mais modernos centros hospitalares, a exemplo das atividades de enfermagem. Ainda mais recente é o caso dos call centers.

Apesar dos inegáveis resultados, o Taylorismo sempre foi alvo de críticas, a mais importante delas sendo a de impor ao operário um comportamento de autômato (Taylor, 1987, p. 116): "por que não me permitem pensar ou agir? Há sempre alguém intervindo ou fazendo por mim”.

Por fim, Henry Ford, notabilizado pela difusão da produção em massa, completa o arcabouço do que veio a ser conhecido como a OCT (acerca das origens da produção em massa, veja, por exemplo, Neffa, 1990, bem como Johnson e Kaplan, 1993). De acordo com Womack, Jones e Roos (1992, p. 14), “a chave para a produção em massa [...] consistia na completa e consistente intercambiabilidade das peças e na facilidade de ajustá-las entre si”. A sequiência abaixo é um conjunto de expressões tiradas do livro A Máquina que Mudou o Mundo. Originalmente distribuídas ao longo do texto-fonte, quando reunidas, como se faz a seguir, permitem que se visualize claramente o que veio a ser denominado de Fordismo:

[...] padronização das medidas por todo o processo [...] redução do número de peças necessárias [...] simplicidade e facilidade [...] plataformas de montagem [...] os 
ORGANIZAÇÃO CIENTÍFICA DO TRABALHO REINVENTA UM MERCADO TRADICIONAL: O CASO DO FITNESS

Ivan Antônio Pinheiro - Rodrigo Reszka Pinheiro

montadores/ajustadores repetiam indefinidamente o mesmo conjunto de atividades [...] completa familiaridade com uma só tarefa permitia ao trabalhador executá-la mais rapidamente [...] minuciosa divisão do trabalho [...] ciclo de trabalho [...] economia de tempo [...] operários de linha tão intercambiáveis quanto as peças do carro [...] divisão do trabalho as suas últimas conseqüências [...] especialização do trabalho precisava apenas poucos minutos de treinamento [...] o processo ocorria automaticamente, toda a habilidade em usinar, assim, passou a se incorporar na máquina (WOMACK, JONES e ROOS, 1992, p. 15-24).

O Fordismo, mais do que revolucionar a forma de gerir os processos internos de produção, trouxe profundas mudanças nas estruturas e no funcionamento dos mais diversos mercados. Produtos padronizados, ditos também homogêneos ou seriados, produzidos em larga escala, e por isso de baixos custos e preços, passaram a conquistar mercados, agora mais complexos, em que a intermediação comercial é fomentada por empresas especializadas em marketing e pelo crédito disponibilizado pelas instituições financeiras. Entre o produtor e o consumidor final se estrutura uma extensa rede de atacadistas, distribuidores e varejistas, entre outras organizações especializadas. A OCT obrigou as organizações a reinventar as formas de fazer negócio.

Os críticos da OCT também enfatizam o seu aspecto desumanizador saliente na excessiva decomposição e especialização dos processos de trabalho, que, se não eliminam, contribuem decisivamente para reduzir substantivamente o espaço para o exercício da liberdade criativa do trabalhador, uma das mais caras condições da natureza humana. Rotinas inflexíveis, excesso de normas e padrões, bem como um ambiente burocratizado, são características sempre associadas à OCT e estariam na raiz, inclusive, do surgimento das doenças físicas e mentais no ambiente de trabalho urbano-industrial do século XX. A metáfora “organização como uma máquina” de Morgan (1996), que mostra o homem como uma parte, ou melhor, tão somente mais uma peça da engrenagem e substituível a qualquer momento, dispensa esclarecimentos adicionais.

Com essa breve história da OCT, pode-se perceber que o modo de produção artesanal, com os riscos que toda generalização acarreta, possui vantagens com relação à OCT. É menos rígida e proporciona maior espaço para o desenvolvimento da criatividade. Mas surgem suas desvantagens como a queda da produtividade e dos volumes gerados com a adoção da OCT. Diante disso, não é comum considerar que no âmbito de um sistema com traços da OCT a criatividade possa se desenvolver. Não obstante, a afirmação contrária será o foco desta investigação. 


\section{ORGANIZAÇÃO CIENTÍFICA DO TRABALHO REINVENTA UM MERCADO TRADICIONAL: O CASO DO FITNESS Ivan Antônio Pinheiro - Rodrigo Reszka Pinheiro}

\section{INOVAÇÃO E CRIATIVIDADE}

Em mercados em que a competição se revela acirrada, ou ainda naqueles já tidos como saturados por apresentar crescimento vegetativo, os ganhos de produtividade proporcionados pela OCT não têm sido suficientes para garantir a continuidade dos negócios. Ademais, a expansão dos mercados, por meio da supressão ou redução das barreiras erguidas pelos governos nacionais, traços do fenômeno referido como globalização, veio a tornar ainda mais aguda a competição entre as empresas. Se a OCT trouxe ganhos significativos para os primeiros que a adotaram, aumentando a distância que mantinham dos concorrentes, o mesmo não se pode dizer dos últimos a fazê-lo. Porque à medida que o tempo passa e se amplia a difusão de uma tecnologia (nesse caso identificada com a OCT), esta adquire um caráter de commodity, assemelhando as organizações, reduzindo as margens de comercialização e, por conseguinte, os ganhos das firmas. Nesse cenário, a opção pela diferenciação por meio da inovação surge como uma das principais estratégias competitivas de que as organizações lançam mão, distinguindo-se dos concorrentes.

Schumpeter foi um dos primeiros a salientar a importância da inovação para a rentabilidade de longo prazo das organizações, vendo na competição existente no mercado a origem de um processo que denominou de "destruição criativa". Entre as formas de inovar o autor identifica o que denomina de "novas combinações":

Introdução de um novo bem, ou seja, um bem com que os consumidores ainda não estiverem familiarizados ou de uma nova qualidade de um bem. 2) Introdução de um novo método de produção, ou seja, um método que ainda não tenha sido testado pela experiência do ramo próprio da indústria de transformação, que de modo algum precisa ser baseada numa descoberta cientificamente nova, e pode consistir também em uma nova maneira de manejar comercialmente uma mercadoria. 3) Abertura de um novo mercado, ou seja, de um mercado em que o ramo particular da indústria de transformação do país em questão não tenha ainda entrado, quer esse mercado tenha existido antes ou não. 4) Conquista de uma nova fonte de oferta de matérias primas ou de bens semi-manufaturados, mais uma vez independentemente do fato de que essa fonte já existia ou teve que ser criada. 5) Estabelecimento de uma nova organização de qualquer indústria, como a criação de uma posição de monopólio (por exemplo, pela trustificação) ou fragmentação de uma posição de monopólio (SCHUMPETER, 1982, p. 48). 
Assim, uma inovação não é necessariamente algo genuinamente novo, até então inexistente, daí os autores que o sucederam terem criado tipologias para caracterizar uma inovação. A mais conhecida e utilizada por vários autores, a exemplo de Christensen (1997), Miller e Morris (1999), é a que distribui as inovações ao longo de contínuo: das inovações incrementais às radicais.

As práticas inovadoras alteram as vantagens competitivas, desestabilizando e reconfigurando o mercado até que este alcance um novo estado de equilíbrio, que, por sua vez, será desestabilizado por outra inovação, reiniciando o ciclo reconhecido por muitos como virtuoso. A importância das inovações tem sido cada vez mais destacada. Stalk Jr. e Hout (1993, p. 117), por exemplo, salientam que a "inovação é a chave para uma vitalidade de longo prazo de qualquer empreendimento", assim como Porter (1998) sublinha que a inovação é a única maneira de desenvolver e sustentar uma vantagem sobre a concorrência, assinalando ainda que a inovação não deve ser um episódio isolado, mas parte integrante de uma estratégia organizacional. Jacobson (1992), na mesma linha, salienta que em um ambiente de negócios inerentemente dinâmico, caracterizado pela incerteza e pelo desequilíbrio, o lucro é uma conseqüência da descoberta e da inovação.

Com isso, a capacidade de inovar para além de uma competência individual deve ser convertida em competência organizacional, um efetivo recurso para os ganhos de competitividade almejados pelas empresas. Assim, uma questão se impõe: como fazer para que uma organização seja reconhecida como inovadora pelo mercado? Vários autores têm contribuído para responder a essa questão (por exemplo, Nonaka e Takeuchi, 1997; Christensen e Raynor, 2003; Kim e Mauborgne, 2005), cada qual a partir de diferentes enfoques e desenvolvendo a sua própria metodologia. Todavia, em um ponto eles convergem: a relevância da criatividade individual, razão pela qual, na seqüência, ela será discutida.

Não obstante a inovação e a criatividade serem temas encontrados sempre juntos na literatura, não há unanimidade entre os autores sobre o que seja esta última. Boden (1999, p. 81), por exemplo, se refere à criatividade como “[...] um quebra-cabeças, um paradoxo, para alguns um mistério”, enquanto Galvão (1999) apresenta mais de 20 definições do que são as pessoas criativas e quais são suas características. Sternberg (2000, p. 332) focaliza as razões da dificuldade de se definir o que é a criatividade: "[...] como podemos definir criatividade como um único constructo que unifica o trabalho de Leonardo da Vinci e Marie Curie, de Vincent Van Gogh e Isaac Newton, de Toni Morrison e Albert Einstein e de Wolgang Mozart e Nicolaus Copernicus?”. Adiante, prossegue ainda o autor (Sternberg, 2000, p. 337): "criatividade é um processo cognitivo que leva à produção de alguma coisa que é ao mesmo tempo original e de valor". Complementando, Vernon, citado por Eysenck (1999, p. 204), identifica a criatividade como sendo "a capacidade de uma pessoa para produzir idéias, concepções, 
invenções ou produtos artísticos novos ou originais, que são aceitos pelos especialistas como tendo valor científico, estético, social ou técnico”.

Embora a criatividade seja um processo verificado no âmbito do indivíduo (Predebon, 1997; Galvão, 1999), muitos fatores externos concorrem para o seu desenvolvimento (Ostrower, 1987; Nonaka e Takeuchi, 1997; Eysenck, 1999), a exemplo da cultura, de aspectos institucionais e do estilo de gestão se o mesmo indivíduo integra uma equipe de trabalho. De forma mais precisa, Eysenck (1999, p. 213) identifica 12 variáveis, agrupadas em três categorias, que atuam sobre a criatividade individual, como mostradas no Quadro 1.

\section{Quadro 1 - Dimensões da criatividade}

\begin{tabular}{|l|l|l|}
\hline \multicolumn{3}{|c|}{ ASPECTOS } \\
\hline \multicolumn{1}{|c|}{ Cognitivos } & \multicolumn{1}{c|}{ Ambientais } & \multicolumn{1}{c|}{ Personalidade } \\
\hline inteligência & fatores político-religiosos & motivação interna \\
\hline conhecimento & fatores culturais & confiança \\
\hline habilidades técnicas & fatores socioeconômicos & não-conformismo \\
\hline talentos especiais & fatores educacionais & criatividade (traço) ${ }^{(*)}$ \\
\hline
\end{tabular}

(*) Diz-se que uma pessoa possui traços de criatividade quando sistematicamente as suas ações são reconhecidas como originais, isto é, dotadas de conteúdo inovador.

Finalmente, apesar de os estudos não serem conclusivos, até mesmo apresentando controvérsias, as pessoas criativas também têm se destacado pelo tipo de comportamento. Martindale (1999, p. 198), citando Eysenck, diz que

[...] se Eysenck (1991) está certo quanto aos determinantes da criatividade, então, para maximizar a criatividade, uma sociedade precisa também maximizar o psicoticismo, individualismo ou egoísmo, pelo menos nas organizações ou segmentos dedicados à produção de idéias criativas [...] a aversão das pessoas criativas a todo tipo de regra, controle e inibição sugere que a sociedade criativa deve minimizar regras e controlar e maximizar a liberdade e a individualidade.

Eysenck (1999, p. 213), por sua vez, comentando o trabalho de Hovecar e Bachelor, afirma que “[...] existem pelo menos algumas evidências de que esses dois construtos [pensamento divergente e personalidade criativa] constituem causas potenciais da criatividade na vida real". Em seguida, o autor prossegue referenciando os trabalhos de Dellas e Gaier: 
ORGANIZAÇÃO CIENTÍFICA DO TRABALHO REINVENTA UM MERCADO TRADICIONAL: O CASO DO FITNESS Ivan Antônio Pinheiro - Rodrigo Reszka Pinheiro

[...] evidências indicam um padrão comum de traços de personalidade entre pessoas criativas, e também que esses fatores de personalidade podem ter alguma base na criatividade em abstrato, independentemente do setor [...] 13 principais traços: (1) independência de atitude e comportamento social; (2) dominação; (3) introversão; (4) abertura a estímulos; (5) interesses amplos; (6) auto-aceitação; (7) intuição; (8) flexibilidade; (9) presença e atitudes sociais; (10) uma atitude anti-social; (11) preocupação com normais sociais; (12) radicalismo; (13) rejeição a restrições externas. (Eysenck, 1999, p. 216).

Conforme se observa, há um nítido contraste entre o perfil das pessoas criativas e o daquelas que, em princípio, seriam as mais ajustadas ao ambiente determinado pela OCT. Mais do que um contraste, pode-se dizer que há uma situação de mútua exclusão, ou seja, onde predomina um ambiente normatizado pela OCT, muito provavelmente são restritas as possibilidades para o desenvolvimento criativo e, por conseguinte, de surgirem inovações. A questão que ora se levanta é a seguinte: sendo a OCT e a criatividade construtos até certo ponto antagônicos, como podem, se combinados, resultar em uma inovação? Isto é o que vem ocorrendo no mercado de fitness, como na sequiência se pretende demonstrar. Ademais, trata-se de uma visão, seguida de uma estratégia organizacional, ainda não devidamente identificada e, por conseguinte, explorada por aqueles que pretendem inovar.

\section{CASO DO FITNESS}

\section{Da calistenia ao fitness}

Antes mesmo do surgimento das civilizações, o homem primitivo era obrigado a lutar pela sobrevivência, ora caçando, ora sendo caçado em um ambiente francamente hostil, o que, certamente, desde o início dos tempos, trouxe à sua consciência a importância do preparo físico. Talvez por essa razão a humanidade tenha registros da prática regular de atividades físicas desde as civilizações mais antigas. Segundo Costa (1996), foi na Grécia Antiga que apareceram os primeiros registros da prática de ginástica, que naquela época era chamada de calistenia $(k a ́ l l o s=b e l o ~+~ s t h e n o s ~=$ força).

Reconhecidos por suas contribuições no campo da filosofia, Sócrates, Platão e Aristóteles foram destacados atletas, os dois últimos por mais de uma vez sagrados campeões nos festivais olímpicos.

Não obstante o fato de que atividades físicas regulares continuassem sendo praticadas, sempre de acordo com as tradições dos povos, nenhuma se assemelha ao que hoje é conhecido como 


\section{ORGANIZAÇÃO CIENTÍFICA DO TRABALHO REINVENTA UM MERCADO TRADICIONAL: O CASO DO FITNESS}

Ivan Antônio Pinheiro - Rodrigo Reszka Pinheiro

“ginástica". Essa realidade perdura até o início do século XIX, quando nos Estados Unidos a calistenia ressurge por iniciativa da Associação Cristã de Moços (ACM), quando então foi definida como

um sistema de ginástica que apresenta como características a predominância de formas analíticas, a divisão dos exercícios em grupos, a associação da música ao ritmo dos movimentos, a predominância dos movimentos sobre as posições e exercícios à mão livre como também com pequenos aparelhos como halteres e bastões (MARINHO, 1980, p. 264$5)$.

Com essas características, a calistenia pode ser considerada a atividade que deu origem a todas as ginásticas que conhecemos nas academias contemporâneas (Costa, 1996). Por meio da ACM, a calistenia se difundiu pelo mundo. No Brasil a calistenia foi o referencial científico para as aulas de ginástica até os anos de 1960-70. Na década seguinte, surge uma nova "moda" nas academias do Rio de Janeiro que logo se espalha pelo país: a ginástica aeróbica. Era o tempo em que tanto a "velha ginástica calistênica" (a grega, hoje mais restrita aos quartéis) quanto a aeróbica (a calistênica revitalizada e praticada nas academias) tinham, no professor, a figura central, a que desempenhava o papel de coreógrafo e de maestro capaz de combinar, com criatividade, movimentos e ritmos, sincronizados em coreografias cuja elegância e harmonia garantiam as salas repletas de alunos.

Nesse ambiente, o professor é também um artista, cujo repertório deveria combinar músicas conhecidas da maioria dos alunos. Assim, não seria de estranhar que, em um país continental como o Brasil, as aulas de aeróbica no Nordeste, por exemplo, incorporassem ritmos daquela região, daí a aeroaxé e a aero-lambada. Para não tornar as aulas monótonas, a coreografia deveria, com freqüência, ser alterada. Ceteris paribus era o tempo em que a fidelidade era maior ao professor do que à academia. Para o professor, além do esforço físico, era exigido um esforço intelectual acompanhado de um maior dispêndio de tempo. Para as academias, práticas de gestão destinadas a garantir a permanência dos seus principais talentos, bem como era maior a dificuldade no caso de ser necessária a substituição de quadros. E, para os alunos, o risco de, quando necessário trocar de academia, o desapontamento com o novo professor-coreógrafo.

Entretanto, a aeróbica deixava a desejar no que diz respeito à força muscular, tendo em vista que visava ao condicionamento cardiorrespiratório dos praticantes. A lacuna existente foi o caminho para o surgimento das salas de halterofilismo, hoje salas de musculação, que em pouco tempo ganharam popularidade e passaram a abrigar mais alunos do que as salas de ginástica (calistenia) nas 
academias. Essa realidade, surgida e desenvolvida na década de 1980, não perdurou muito. Em meados da década de 1990 o mundo da ginástica no Brasil assistiu a uma reinvenção: a revolução do fitness.

\section{Surge um mercado}

Doenças como a obesidade, distúrbios cardiovasculares e problemas de postura surgiram devido a mudanças nos hábitos de vida. Essas foram provocadas pelo processo de urbanização, sobretudo os hábitos ligados aos meios de transporte, ao tipo de alimentação e às formas de lazer, associadas ainda ao modelo de trabalho instituído pela OCT, baseado em movimentos padronizados e reproduzidos indefinidamente. Surge, assim, um mercado para o fitness, no mundo e no Brasil.

Ademais, decorrente da forma de organização e de gestão da produção dominante nas fábricas, cuja produtividade, conforme visto, aumenta na razão em que os produtos são padronizados, a expansão das indús trias e do mercado de vestuário pret-à-porter requer clientes também padronizados ou que, pelo menos, apresentem limitada variação nas dimensões básicas. Surgem os padrões de beleza em ciclos (a moda), rapidamente disseminados pelos meios de comunicação de massa, sobretudo na mídia impressa e na televisão.

Impulsionado pelos que procuram melhor qualidade de vida e saúde e por aqueles que anseiam os padrões de beleza socialmente valorizados, cresce o mercado de fitness. Segundo estimativas da Associação Brasileira de Academias, as suas 7 mil filiadas atendem a um público de aproximadamente 5,6 milhões de pessoas (Confef, 2004). A ausência de pesquisas regulares, metodologicamente confiáveis e isentas, reduz a crença em determinadas afirmações. Todavia, uma visita às academias permite verificar o perfil e a preocupação dominante dos frequientadores: jovens com o intento de modelar o corpo para estar de acordo com os padrões atuais de beleza. Mais recentemente, observa-se que a ginástica tradicional - aula preparada pelo professor-coreógrafo-artista - cede espaço para uma nova forma de atividade física: a ginástica pré-coreografada.

\section{REVOLUÇÃO DO FITNESS: O CASO DA LES MILLS - BODY SYSTEMS}

Nascida como um empreendimento familiar em 1968, uma iniciativa e realização dos familiares adeptos de práticas esportivas, a Les Mills apresentou rápido crescimento e, em 1970, a partir da sua sede em Auckland, já se expandia para o resto da Nova Zelândia. A partir daí, a sua trajetória se assemelha à de tantas outras organizações que, nascidas a partir de um produto que logrou ampla 
aceitação no mercado, no caso a ginástica pré-coreografada, deu origem a um novo modelo de negócios: a franquia, especificamente a Les Mills International. Resultado da ação de 16 distribuidores, em 2003 o seu método já era utilizado em aproximadamente 8 mil academias localizadas em cerca de 50 países (Les Mills, 2004).

A proposta da Les Mills é oferecer um modelo único de ginástica, com marca, identidade visual, músicas e projeto de marketing próprios às academias que aderirem ao programa na forma de franquia. As vantagens para as academias podem ser vistas no website da Body Systems do Brasil (2004), franqueada da corporação neozelandeza, quais sejam: padronização do serviço, treinamento da equipe de professores, associação da marca da academia à marca bem-sucedida da empresa, direito à utilização do material de marketing dos programas de ginástica (a exemplo dos pôsteres, CDs e jornais internos) e suporte técnico e administrativo à academia, coordenados a partir de São Paulo, de onde a Body Systems se articula com as suas subfranqueadas.

Dez anos após a sua implantação no Brasil o método já tem adesão de 1.700 academias distribuídas em todos os estados (Body Systems do Brasil, 2004). O produto ofe recido pela Les Mills compreende sete subprodutos (modalidades de ginástica denominadas de programas), cada qual correspondente a uma franquia independente: 1) BodyAttack, 2) BodyBalance; 3) BodyCombat; 4) BodyJam; 5) BodyPump; 6) BodyStep; e 7) RPM. Cada modalidade visa atender às necessidades e preferências de públicos específicos. Dessa forma, os adeptos de lutas marciais se encontram nas classes de BodyCombat, os do ioga nas de BodyBalance, os que preferem a musculação optam pelo BodyPump, enquanto os que gostam de ritmos mais descontraídos e bailados se reúnem nas turmas de BodyJam. Cabe esclarecer que nas aulas de BodyCombat não há, como nas academias de luta, contato físico, mas tão somente a simulação de movimentos adaptados do tai chi chuan, do tae kwon do e do kickboxing. Raciocínio análogo se aplica às demais modalidades.

Mas no que se baseia o método da Les Mills e qual a razão da sua popularidade? O periódico $B S$ News (2001) estabelece que a BodyAttack é

conhecida como a aula mais intensa entre os programas (...) a fórmula é simples: trabalho intervalado de alta intensidade, porém de baixa complexidade, ou seja, movimentos fáceis e desafiadores ao mesmo tempo (...) é um programa para quem deseja condicionamento físico total. A aula é dividida em três picos de trabalho cardiovascular e de intensidade progressiva. Estes picos são alternados com recuperações ativas de exercícios localizados, como flexões de braços e agachamentos. Resultado: braços fortes, pernas fortes, coração forte! 
A analogia com a escala musical facilita o entendimento acerca dos programas, bem como das suas vantagens. Assim como a partir das sete notas básicas, conhecidas por todos, é possível compor as mais diversas melodias, pois a partir de um conjunto básico e simples de movimentos são criadas as coreografias dos diversos programas. Dessa forma, coreografias fáceis e acompanhadas pelos sucessos musicais mais conhecidos no mundo inteiro tornaram o Body System popular. A Les Mills assegura aos seus franqueados e adeptos que todas as modalidades são prévia e cientificamente testadas em sujeitos de pesquisa acompanhados em modernos laboratórios de biomecânica e fisiologia, tendo por objetivo a eliminação dos desconfortos, das possibilidades de acidentes, e garantir o máximo rendimento. Finalmente, a cada três meses - da sua sede em Auckland - são lançadas as novas coreografias para todas as modalidades, constituindo um novo mix (atualmente há mais de 40 deles) que, após o devido treinamento conferido aos professores, são apresentados em eventos marcados pelo espírito de confraternização, quando os adeptos de cada modalidade (BodyCombat, BodyJam por exemplo) são convidados a praticar todas as demais. Cada instrutor pode se especializar e obter credenciamento em uma ou mais modalidades. Com isso, a cada trimestre, somente após a conclusão e aprovação no programa de capacitação, os instrutores terão as suas credenciais renovadas, podendo, dessa forma, continuar a exercer a atividade em quaisquer das academias franqueadas no Brasil e no mundo.

A rápida expansão desses programas sinaliza a sua franca aceitação pelo público freqüentador de academias. Quais seriam as razões do sucesso do que se pode chamar de "modelo Les Mills"? Sem dúvida, são inúmeros os fatores que concorreram e a seguir são listados alguns: 1) ter identificado, atraído e reunido em um só local, para a prática de atividades físicas, um público até então segmentado entre freqüentadores das academias de danças, ioga e musculação; 2) ter simplificado e padronizado movimentos de maior complexidade, tornando-os acessíveis a um conjunto maior de praticantes, alguns até então auto-excluídos dessas atividades; 3) ter conseguido desenvolver um eficiente e eficaz sistema de gestão de franquia, oferecendo suporte técnico, gerencial e mercadológico aos franqueados.

\section{Mercado em transformação}

A ampla aceitação da ginástica pré-coreografada trouxe a reboque a abertura de novos negócios, em escala também mundial, de mercados correlatos ao de fitness. Entre eles, o do vestuário, também padronizado, para as práticas esportivas que nesse caso ainda se apresenta segmentado conforme a modalidade seguida pelo praticante. Por exemplo, os praticantes de BodyCombat são identificados pelo uso de roupas em que predomina uma determinada cor, enquanto os de BodyAttack se distinguem por 
outra. Todos juntos, circulando nos eventos trimestrais que marcam o lançamento dos novos mixes, conferem um singular colorido à alegria do ambiente, assim como a cor é a maneira de se identificar e ser reconhecido na já ampla comunidade de iniciados, isto é, em qualquer academia franqueada, no Brasil e no mundo, que venha a freqüentar. Lembrando que esse modelo de negócios vem se impondo no mundo, é fácil avaliar o potencial de mercado desse segmento da indústria têxtil. Paralelamente, cresce o mercado de acessórios, a exemplo de caneleiras, tornozeleiras e bandanas.

Por determinação contratual, as seqüências musicais dos programas podem apenas ser apresentadas nas aulas específicas e pelos instrutores credenciados após treinamento e avaliação, repetindo-se a cada lançamento de mix. Não há notícias, mas a composição de músicas exclusivas e dedicadas a determinadas coreografias pode ser o próximo passo, não só por reduzir os gastos com licenciamento da franqueadora como pela possibilidade de vir a ser uma nova fonte de receitas.

A expansão verificada nesse mercado faz crer que outros produtos venham a complementar e a ampliar a linha já existente: agasalhos (joggings), calçados esportivos, adereços e bebidas energéticas e cientificamente balanceadas. No segmento de cosméticos, cremes e loções específicas. São produtos que apresentam custos reduzidos e que, se produzidos em larga escala e associados a uma grife, elevam o valor agregado, proporcionando grandes margens de lucros.

Enfim, movimentos simples, padronizados, cientificamente estudados, sucessos musicais sempre presentes na memória dos freqüentadores, reunidos em coreografias harmônicas, compõem o novo ambiente e o mercado do fitness. Uma estrutura corporativa de origem familiar que soube se profissionalizar e se expandir por meio da franquia, oferecendo o devido suporte aos franqueados. Tudo precisamente planejado e articulado para atrair e fidelizar o freqüentador de academias.

Inovação bem-sucedida, o método e a estratégia das Les Mills hoje enfrentam concorrentes. Todavia, os princípios da pioneira são seguidos por todos, o que acentua essas características como uma mudança que se afirma no modelo de negócios prevalecente nesse mercado. No entanto, a exemplo da maioria das inovações, tal como já mencionado, o fitness também enfrenta críticas, tema da próxima seção.

\section{Análise crítica}

No Brasil, entre os profissionais de Educação Física, que de acordo com a Lei Federal n 9.696/98 (Brasil, 1998) são os únicos considerados habilitados a ministrar aulas de ginástica, não há consenso a respeito do impacto das mudanças que se verificam nesse mercado de trabalho. Há quem defenda que a 
disseminação de ginásticas pré-coreografadas limita a atuação do profissional no momento da criação das suas próprias aulas e, conseqüentemente, desvaloriza a atuação profissional, uma vez que repetir uma coreografia é mais simples do que criá-la. Entretanto, há quem argumente a favor, justificando que essas ginásticas elevaram o público freqüentador das academias e possibilitaram a abertura de novos postos de trabalho. Entre os que argumentam contra as ginásticas pré-coreografadas, Geraldes (1993, p. 14) firma sua posição dizendo que

torna-se necessário que os profissionais de nossa área sejam realmente habilitados para trabalhar, não podemos ser infantis a ponto de imaginar que microcursos de 12 a 36 horas possam preparar profissionais [...] a trabalhar com material humano [o autor se refere aos programas de credenciamento desenvolvido pelas franqueadoras]. Infelizmente, esta é a realidade. Cada vez mais, aumenta o número de indivíduos que com microcursos [...] estão dentro de salões cenograficamente montados, com iluminação, efeitos especiais com fumaça, instrumentos musicais, com baterias e até fantasias. Este 'set' de filmagem, que faria inveja até à MGM americana, inundou a realidade do país.

Freire (2004), na mesma linha argumentativa, afirma que as ginásticas pré-coreografadas são a expressão da uniformização das pessoas e do desrespeito às diferenças individuais no mundo da Educação Física. O trecho a seguir, extraído do seu artigo que leva o sugestivo título de BodyStupid, traduz as idéias que defende,:

O corpo dá lucro, muito lucro, descobriram finalmente. Para que perder tempo com Universidades, gastar neurônios com essa coisa de ciência, cultura popular, filosofia? Nunca o mito de Narciso esteve tão vivo quanto no reino dos bodys. Nunca os gestos foram tão precisos, nunca os espelhos tão valorizados. Bunda para trás, peito para frente (sorrisos), músculos rompendo a pele (FREIRE, 2004, s.p).

O professor, ao lado do aluno e da administração da academia, é o terceiro vértice do fitness. Uma crítica dos profissionais de Educação Física às ginásticas pré-coreografadas é a de que o professor perde a oportunidade de criar e de inovar nas suas aulas. O seu papel é reduzido, podendo até mesmo ser eliminado, passando este a ser um mero transmissor de uma "aula" que eventualmente até poderia ter sido aprendida por meio de um vídeo adquirido pelo seu empregador. Esse professor passa a ser apenas uma peça de uma engrenagem. Se a peça estragar, basta substituí-la por outra do mesmo modelo 
e, se o preço da peça (salário) fica mais elevado, há sempre a opção de substituí-la por outra mais barata, pois o intercâmbio está assegurado.

As próprias empresas salientam esse aspecto nos materiais destinados aos proprietários de academias: "é fundamental poder substituir profissionais nos momentos de ausência dos titulares, como férias, faltas e outras ocorrências, sem que isso ocasione a insatisfação dos clientes" (Body Systems do Brasil, 2004). Indubitavelmente essa flexibilidade, também presente à mesa de negociações que envolvem questões salariais e alterações nas jornadas de trabalho, fragiliza o profissional empregado perante o empregador.

Mais ponderado e observando por outra perspectiva, Goia (2004) defende que, apesar das limitações impostas pelo método, sempre haverá espaço para os professores criativos. Esses, passadas três, quatro semanas do lançamento do mix, tendo percebido que ele já não está estimulando a turma, buscarão em outro mix as músicas e coreografias que já sabem ser do agrado dos alunos, criando, assim, o seu "mix individual" e conferindo um novo dinamismo às aulas. Ademais, a motivação, a garra e a empatia estabelecida pelo professor com a turma, além daquele toque pessoal que não descaracteriza a coreografia básica, são elementos que podem vir a distinguir os profissionais no mercado, reconhecendo o mérito e o valor dos mais criativos. Isso porque a taxa de desistência, tanto dos iniciantes quanto dos mais experientes, atribuída às deficiências dos professores, também é elevada. Portanto, a criatividade ainda é um requerimento essencial para fidelizar o aluno-cliente.

Uma outra linha de críticas vem da provável inadequação dos movimentos e das intensidades com que são praticados, uma vez que, à exceção das ginásticas desenvolvidas no Brasil, as franquias importadas foram testadas com biótipos e em condições climáticas diversas das existentes no país. Por fim, há que se registrar que não foram encontrados, em nenhum dos websites pesquisados, alertas quanto à necessidade de uma prévia e completa avaliação das condições físicas dos candidatos a praticantes. Essa condição deveria ser apresentada $œ m$ destaque, pois não resta dúvida de que o público-alvo é formado por jovens e adultos saudáveis. Os mais obesos, os idosos e as pessoas com baixa coordenação motora, bem como os portadores de cardiopatias, entre outras doenças crônicas, antes de tudo, e sem exagero, correm efetivo risco de vida, sem falar na desmotivação por desinformação que pode suceder à primeira aula.

\section{FITNESS, OCT, CRIATIVIDADE E INOVAÇÃO}


ORGANIZAÇÃO CIENTÍFICA DO TRABALHO REINVENTA UM MERCADO TRADICIONAL: O CASO DO FITNESS

Ivan Antônio Pinheiro - Rodrigo Reszka Pinheiro

Dando início aos encaminhamentos finais, faz-se conveniente um breve resgate para enfatizar algumas analogias existentes entre o marco de referência utilizado pelos autores nas seções antecedentes, conforme mostrado no Quadro 2.

Quadro 2 - Analogias entre os marcos de referências (o artesanato e a OCT) e os tipos de ginástica

\begin{tabular}{|c|c|c|c|}
\hline \multirow{2}{*}{$\begin{array}{l}\text { Arranjos } \\
\text { de } \\
\text { Produção }\end{array}$} & \multicolumn{2}{|c|}{ Algumas Características: } & \multirow{2}{*}{$\begin{array}{c}\text { Tipos } \\
\text { de } \\
\text { Ginástica }\end{array}$} \\
\hline & Dos Arranjos de Produção & Dos Tipos de Ginástica & \\
\hline \multirow{3}{*}{ Artesanato } & $\begin{array}{l}\text { Tarefas individuais mais } \\
\text { completas e complexas }\end{array}$ & $\begin{array}{l}\text { O professor deve reunir } \\
\text { conhecimento de música, } \\
\text { harmonia, coreografia }\end{array}$ & \multirow{3}{*}{$\begin{array}{c}\text { Aeróbica, } \\
\text { localizada e } \\
\text { outras não pré- } \\
\text { coreografadas }\end{array}$} \\
\hline & Produtos diferenciados & $\begin{array}{l}\text { Cada professor cria a sua } \\
\text { própria aula. Diferenças locais e } \\
\text { regionais }\end{array}$ & \\
\hline & $\begin{array}{l}\text { O artesão concebe e produz } \\
\text { o seu produto }\end{array}$ & $\begin{array}{l}\text { Foco na capacidade criativa do } \\
\text { professor }\end{array}$ & \\
\hline \multirow{4}{*}{ OCT } & $\begin{array}{l}\text { Separação entre concepção } \\
\text { (projeto) versus produção }\end{array}$ & $\begin{array}{l}\text { Sistema de franquia: } \\
\text { desenvolvimento versus } \\
\text { execução }\end{array}$ & \multirow{4}{*}{$\begin{array}{l}\text { Pré- } \\
\text { coreografada }\end{array}$} \\
\hline & Operador de processos & Professor como retransmissor & \\
\hline & $\begin{array}{l}\text { Grandes volumes de } \\
\text { produtos não diferenciados }\end{array}$ & $\begin{array}{l}\text { Músicas e coreografias } \\
\text { idênticas, independentemente do } \\
\text { professor, da academia e da } \\
\text { localidade }\end{array}$ & \\
\hline & $\begin{array}{l}\text { Tempos e movimentos } \\
\text { predefinidos, decompostos e } \\
\text { simples }\end{array}$ & $\begin{array}{l}\text { Conjunto de movimentos } \\
\text { básicos intercalados }\end{array}$ & \\
\hline
\end{tabular}

Mas se há semelhanças entre o fitness e a OCT, há também que se acentuar uma diferença, a exemplo da ausência de supervisão funcional concomitante à produção, isto é, no transcurso da aula. Conforme visto, por iniciativa de um empreendedor, um conjunto de antigos princípios e técnicas (a OCT) deu origem a uma efetiva inovação no mercado de fitness. O caso é ilustrativo das múltiplas dimensões que as inovações, tal como Schumpeter (1992) observou, podem assumir: 1) no produto (o fitness); 2) no processo (a utilização dos princípios da OCT); 3) na forma de comercializar e difundir (a franquia); e, por fim, 4) na concepção de um novo modelo de negócios ajustado à realidade dos mercados globalizados. Ademais, surgem novos atores na cadeia industrial: o franqueador 
internacional, o franqueador nacional, indústrias de marcas e grifes associadas aos mais variados produtos e acessórios, bem como produtores de equipamentos dedicados, todos disputando clientes globais. Adicionalmente, modificam-se os antigos papéis e o relacionamento entre a administração das academias, os professores e os alunos.

Nesse caso, contrário a tantos outros, em que as inovações surgem a partir das novas tecnologias, as inovações tiveram origem na percepção criativa de um efetivo empreendedor schumpeteriano que identificou nos conhecidos e antigos princípios da OCT, talvez mesmo sem o saber, uma nova maneira de atender uma demanda contemporânea e crescente em nível global: o culto ao corpo. Importa destacar a sagaz precisão do empreendedor, que soube identificar o problema em cada uma das suas múltiplas dimensões, bem como a solução, também multiforme, para explorar uma oportunidade de negócios. Ademais, talvez em razão da natureza da própria atividade objeto deste estudo, assim como pelo fato de que a OCT nela não se apresenta por inteiro, fez com que não se manifestasse a incompatibilidade entre OCT, criatividade e inovação, sempre referidas na literatura. No caso, a introdução da OCT no mercado de fitness revelou-se como a solução criativa que assegurou a renovação e a expansão desse mercado. Por fim, conforme observado, em que pese a padronização introduzida, resta espaço, ainda que circunscrito, para o exercício da criatividade pessoal do professor.

Em uma primeira avaliação, dado que se trata de fenômeno recente, é de se esperar que venha a acontecer algo semelhante ao verificado nos setores em que a OCT logrou expansão. O Quadro 3 finaliza essa seção e corresponde a uma tentativa de síntese no sentido de avaliar as vantagens e desvantagens conforme a perspectiva de cada um dos principais atores que atuam no processo e no ambiente analisado. 
ORGANIZAÇÃO CIENTÍFICA DO TRABALHO REINVENTA UM MERCADO TRADICIONAL: O CASO DO FITNESS

Ivan Antônio Pinheiro - Rodrigo Reszka Pinheiro

Quadro 3 - Vantagens versus desvantagens da ginástica pré-coreografada conforme as diferentes perspectivas

\begin{tabular}{|c|c|c|c|}
\hline \multirow{4}{*}{$\begin{array}{l}\mathbf{V} \\
\mathbf{a} \\
\mathbf{n} \\
\mathbf{t} \\
\mathbf{a} \\
\mathbf{g} \\
\mathbf{e} \\
\mathbf{n} \\
\mathbf{s}\end{array}$} & Academia & Professor & Aluno \\
\hline & $\begin{array}{l}\text { Explorar a identificação } \\
\text { com marca bem-sucedida }\end{array}$ & $\begin{array}{l}\text { Menor dispêndio de } \\
\text { tempo para criar } \\
\text { coreografias }\end{array}$ & $\begin{array}{l}\text { Maior facilidade para } \\
\text { trocar de academia, uma } \\
\text { vez que os programas são } \\
\text { os mesmos }\end{array}$ \\
\hline & $\begin{array}{l}\text { Suporte técnico, } \\
\text { administrativo e } \\
\text { mercadológico da } \\
\text { franqueadora }\end{array}$ & $\begin{array}{l}\text { Aproveitamento da } \\
\text { mesma coreografia em } \\
\text { várias aulas e academias }\end{array}$ & $\begin{array}{l}\text { Possibilidade de encontrar } \\
\text { o mesmo "produto" por } \\
\text { preços melhores }\end{array}$ \\
\hline & $\begin{array}{l}\text { Maior facilidade para } \\
\text { substituir professores }\end{array}$ & $\begin{array}{l}\text { O treinamento único } \\
\text { confere credencial para } \\
\text { atuar em várias academias } \\
\text { (empregos) }\end{array}$ & $\begin{array}{l}\text { Continuação do "seu } \\
\text { programa" mesmo } \\
\text { quando em viagens } \\
\text { internacionais }\end{array}$ \\
\hline $\begin{array}{l}\text { D } \\
\text { e } \\
\text { S } \\
\text { v } \\
\text { a }\end{array}$ & $\begin{array}{l}\text { Perda de identidade: mais } \\
\text { uma no mercado }\end{array}$ & $\begin{array}{l}\text { Dependente de um fluxo } \\
\text { contínuo de treinamento } \\
\text { às suas expensas sob pena } \\
\text { de perder o } \\
\text { credenciamento }\end{array}$ & $\begin{array}{l}\text { Falta de opção, devendo } \\
\text { se enquadrar na(s) } \\
\text { modalidade(s) } \\
\text { licenciada(s) pela(s) } \\
\text { academia(s) }\end{array}$ \\
\hline $\begin{array}{l}\mathbf{t} \\
\mathbf{a} \\
\mathrm{g} \\
\mathrm{e}\end{array}$ & $\begin{array}{l}\text { Com o tempo, criar } \\
\text { dependência da } \\
\text { franqueadora, atrelando a } \\
\text { ela o seu destino }\end{array}$ & $\begin{array}{l}\text { Maior risco de } \\
\text { substituição }\end{array}$ & $\begin{array}{l}\text { Pode ocorrer, a médio } \\
\text { prazo, desânimo motivado } \\
\text { pela monotonia. }\end{array}$ \\
\hline $\begin{array}{l}\text { n } \\
\text { s }\end{array}$ & & $\begin{array}{l}\text { Para os mais criativos, } \\
\text { redução do espaço para o } \\
\text { seu exercício }\end{array}$ & \\
\hline
\end{tabular}

\section{CONSIDERAÇÕES FINAIS}

Este trabalho teve por objetivo demonstrar que velhas práticas como a OCT, combinada a outra, não tão antiga como a franquia, podem orientar inovações que repercutem e redefinem estruturas de mercados. Embora a OCT possa se caracterizar como um ambiente adverso ao pleno exercício da criatividade, é preciso ser criativo para, combinando-a com outras práticas e estratégias, promover uma inovação que, na perspectiva de alguns, é radical. Assim é verdade que no plano organizacional, no âmbito micro, a OCT restringe, mas não elimina, a criatividade em um plano mais abrangente, como o 
dos modelos de negócios e de mercados, trazendo imensos desafios e possibilidades à necessária inovação. Assim, o paradoxo criatividade versus inovação versus OCT foi explicado, posto que, antes de ser generalizado, deve ser qualificado de acordo com o nível de análise.

Em se tratando de um fenômeno recente, a avaliação prospectiva e definitiva dos impactos do fitness, tal como apresentado neste artigo, ainda é tarefa a ser realizada. Todavia alguns movimentos já observados no passado e nos mercados de massa podem vir a repetir-se no ambiente analisado. Assim, é possível que, à medida que a ginástica pré-coreografada ganhe difusão, algumas academias adotem iniciativas no sentido oposto, como uma estratégia calcada na customização dos seus produtos, posicionando-se de forma distinta. Se hoje os fornecedores industriais de roupas, acessórios e equipamentos dedicados estão a serviço do fitness, a expansão daqueles mercados pode vir a modificar a polaridade das forças competitivas, causando impactos, em âmbito individual, na relação dos custos versus benefícios da ginástica pré-coreografada, pois, no caso das roupas, embora não seja obrigatória, há a possibilidade de imposição social ou, pelo menos, que assim seja percebida pelo indivíduo no seu grupo, sobretudo pelos mais jovens e que não têm independência financeira. Se, por iniciativa da franqueadora, aos custos dos equipamentos (obrigatórios) somarem-se outros, como, por exemplo, quotas de venda de roupas e acessórios, algumas academias poderão sair do mercado, sobretudo se perdurarem as dificuldades econômicas do país.

Também não deve ser perdido de vista que o vínculo estratégico entre as academias locais, a franqueadora nacional e a franqueadora internacional possui de duplo sentido. Se há créditos que inicialmente são os mais evidentes, há também a possibilidade de ocorrências indesejáveis, como um escândalo que comprometa a imagem e até saúde financeira desta última. Portanto, se há bônus, mais evidentes, também há os ônus, nem tão evidentes. A pirataria, infelizmente presente em vários setores, também encontra um campo fértil para o seu desenvolvimento, nada impedindo, por exemplo, que as músicas (no formato de CDs) sejam copiadas e as coreografias aprendidas por alunos de uma academia, mas que atuam como professores em outras. Combinar a velha e a nova aeróbica, obtendo credenciamentos parciais, mix sim, mix não, por exemplo, pode ser uma alternativa para os professores que pretendem reduzir os custos de capacitação. A diluição dos custos entre grupos de profissionais, cada um obtendo credenciamento específico e depois compartilhando entre si, também é uma ameaça ao modelo de negócios analisado.

Por fim, são conhecidos os alcances e as limitações dos ensaios exploratórios, bem como da pesquisa participante como estratégia investigatória. Contudo, o propósito deste artigo não foi buscar generalizações e tampouco fechar questões; antes, ao contrário, os autores pretenderam analisar um 
ORGANIZAÇÃO CIENTÍFICA DO TRABALHO REINVENTA UM MERCADO TRADICIONAL: O CASO DO FITNESS Ivan Antônio Pinheiro - Rodrigo Reszka Pinheiro

fenômeno ainda recente e que requer continuados estudos, tendo inclusive alguns dos caminhos já sido apontados neste estudo.

\section{REFERÊNCIAS BIBLIOGRÁFICAS}

BODEN, M. A. O que é a Criatividade? In: BODEN, M. A. (Org.). Dimensões da Criatividade. Porto Alegre: Artes Médicas, 1999. p. 81-123.

BODY SYSTEMS DO BRASIL. Disponível em: 〈http://www.bodysystems.com.br>. Acessado em: 15 abr. 2004.

BRANDÃO, Carlos Rodrigues (Org.). Pesquisa Participante. 2a . reimpressão da 8. ed. São Paulo: Brasiliense, 2001.

BRASIL. Lei Federal no. 9.696, de 01 de setembro de 1998. Dispõe sobre a regulamentação da Profissão de Educação Física e cria os respectivos Conselho Federal e Conselhos Regionais de Educação Física. Disponível em: 〈http://www.senado.gov.br〉. Acessado em: 23 abr. 2004.

BS NEWS. News Body Systems. São Paulo, a. IV, n. 10, out.-dez. 2001.

CHRISTENSEN, C. M. The Innovator's Dilemma. Boston: Harvard Business School Press, 1997.

CHRISTENSEN, C. M.; RAYNOR, M. E. O Crescimento pela Inovação. Rio de Janeiro: Elsevier, 2003.

CONFEF - Conselho Federal de Educação Física. Rio de Janeiro, Educação Física, ano III, n. II, março 2004.

COSTA, M. G. da. Ginástica Localizada. Rio de Janeiro: Sprint, 1996.

DESCARTES, R. Dircurso do Método. São Paulo: Nova Cultural, 2000. [Coleção os Pensadores]. 
EYSENCK, H J. As Formas de Medir a Criatividade. In: BODEN, M A. (Org.). Dimensões da Criatividade. Porto Alegre: Artes Médicas, 1999. p. 203-44.

FREIRE, J. B. Body Stupid. Disponível em: 〈http:www.decorpointeiro.com.br>. Acessado em: 15 mai. 2004.

GALVÃO, M. Criativamente. 2. ed. Rio de Janeiro: Qualitymark, 1999.

GERALDES, A. A. R. Ginástica Localizada: teoria e prática. Rio de Janeiro: Sprint, 1993.

GOIA, P. Professor de Educação Física e Coordenador de Atividades Físicas na ACM-RS, Porto Alegre. Entrevista aos autores em 15 abr. de 2004.

LES MILLS. Disponível em: <http:www.lesmills.com>. Acessado em: 21 abr. 2004.

JACOBSON, R. The Austrian School of Strategy. Academy of Management Review, v.17, n. 4, p. 782$807,1992$.

JOHNSON, H. T.; KAPLAN, R. S. Contabilidade Gerencial: a restauração da relevância da contabilidade nas empresas. Rio de Janeiro: Campus, 1993.

KIM, W. C.; MAUBORGNE, R. A Estratégia do Oceano Azul. 5. ed. Rio de Janeiro: Elsevier, 2005.

MARINHO, I. P. Sistemas e Métodos de Educação Física. São Paulo: Papelivros, 1980.

MARTINDALE, C. Como Podemos Medir a Criatividade de uma Sociedade? In: BODEN, Margareth A. (Org.). Dimensões da Criatividade. Porto Alegre: Artes Médicas, 1999. p. 165-202.

MILLER, W. L.; MORRIS, L. Fourth Generation R\&D. USA, Canada: John Wiley, 1999.

MORGAN, G. Imagens da Organização. São Paulo: Atlas, 1996. 
ORGANIZAÇÃO CIENTÍFICA DO TRABALHO REINVENTA UM MERCADO TRADICIONAL: O CASO DO FITNESS Ivan Antônio Pinheiro - Rodrigo Reszka Pinheiro

NEFFA, J. C. El Proceso de Trabajo y la Economia de Tiempo - contribución al análisis crítico de K. Marx, F. W. Taylor y H. Ford. Buenos Aires: CREDAL-HVMANITAS, 1990.

NONAKA, I.; TAKEUCHI, H. Criação de Conhecimento na Empresa. 11. ed. Rio de Janeiro: Campus, 1997.

OSTROWER, F. Criatividade e Processos de Criação. 16. ed. Petrópolis: Vozes, 1987.

PORTER, M. Criando as Vantagens Competitivas de Amanhã. In: GIBSON, R. (Ed.). Repensando o Futuro. São Paulo: Makron Books, 1998.

PREDEBON, J. Criatividade - abrindo o lado inovador da mente. São Paulo: Atlas, 1997.

SCHUMPETER, J. A. A Teoria do Desenvolvimento Econômico. São Paulo: Abril Cultural, 1982. [Coleção: Os Economistas.]

SMITH, A. Investigação sobre a Natureza e as Causas da Riqueza das Nações. 2. ed. São Paulo: Abril Cultural, 1979. [Coleção os Pensadores.]

STALK JR., G.; HOUT, T. M. Competindo Contra o Tempo. Rio de Janeiro: Campus, 1993.

STERNBERG, R. J. Psicologia Cognitiva. Porto Alegre : Artes Médicas, 2000.

TAYLOR, F. W. Princípios de Administração Científica. 7. ed. São Paulo: Atlas, 1987.

VILLA-ALVAREZ, F. Iniciação à Metodologia de Pesquisa Científica. Brasília: FUNCEP/ENAP, 1988.

WOMACK, J. P.; JONES, D. T.; ROOS, D. A Máquina que Mudou o Mundo. 3. ed. Rio de Janeiro: Campus, 1992. 


\section{Artigo recebido em 28.04.2004. Aprovado em 02.03.2006.}

\section{Ivan Antônio Pinheiro}

Professor no Programa de Pós-Graduação em Administração da UFRGS. Doutor em Administração pela Universidade Federal do Rio Grande do Sul.

Interesse de pesquisa nas áreas de gestão da inovação, gestão da produção e administração pública em geral, e reforma do Estado (organizações sociais, regulação, PPP, contratos de gestão).

E-mail: iapinheiro@ea.ufrgs.br

Endereço: Rua Washington Luiz, 855/444, Porto Alegre - RS, 91.010-460.

\section{Rodrigo Reszka Pinheiro}

Professor no curso de Turismo e Hotelaria do CEPUTEC. Especialista em Educação Física Escolar pela FACVEST - Faculdades Integradas da Rede de Ensino UNIVEST.

Interesse de pesquisa nas áreas de lazer e animação sociocultural, empreendedorismo e inovações no mercado de entretenimento.

E-mail: rodrigo@animacaoeltda.com.br

Endereço: Rua Evaldo Schaeffer, 422, bloco B10, ap. 13, Florianópolis - SC, 88.095-350. 